\title{
PERBANDINGAN NILAI MARSHALL DASPAL (DAMAR ASPAL) DI LABORATORIUM DENGAN HASIL CORING DI LAPANGAN SERTA ANALISIS SKID RESISTANCE
}

\author{
Satria Lima Santara ${ }^{1)}$, Ary Setyawan ${ }^{2}$, Agus Sumarsono ${ }^{3)}$ \\ 1) Mahasiswa Program Studi Teknik Sipil Universitas Sebelas Maret \\ 2)3) Pengajar Program Studi Teknik Sipil Universitas Sebelas Maret \\ Jalan Ir. Sutami No.36A Surakarta 57126 Telp: 0271647069.Email : satriasantara@yahoo.co.id
}

\begin{abstract}
The needs of conventional asphalt is increasing so that requires another material as substitution that called bioasphalt. One of the innovations that being developed is daspal (asphalt resin). The purpose of this research is to compare test objects of daspal made in the laboratory with test objects cored in the field with rolling variations using Marshall test and skid resistance. The method in this research is experimental in the laboratory and on the field. The rolling variations on the field are 6 times, 10 times and 14 times. Before the coring process is done, skid resistance is tested with rolling straightedge tool on the field. Then, coring on each rolling variation is done to take test objects for Marshall test field. The composition of daspal is powder resin (350 gr), chunk resin (100gr), cooking oil (205), fly ash (150 gr), and latex (4\%). The result and analysis of Marshall test from the laboratory test objects have showed that the value of stability 1118,519 $\mathrm{kg}$, flow 4,65 mm, and MQ 241,102 $\mathrm{kg} / \mathrm{mm}$. The values of the skid resistance test are $9,83 \mathrm{~mm} / \mathrm{m}$ for 6 times rolling, $8,83 \mathrm{~mm} / \mathrm{m}$ for 10 times rolling, and 7,67 $\mathrm{mm} / \mathrm{m}$ for 14 times rolling. V alues of stability, flow, and $M Q$ from the laboratory test objects are greater than the field coring test objects for all rolling variations. While, the greater of the skid resistance value indicates that the surface texture is flatter.
\end{abstract}

Key words : Daspal, Marshall, Skid Resistance

\begin{abstract}
Abstrak
Kebutuhan akan aspal konvensional yang terus meningkat membutuhkan alternatif penggunaan bahan lain sebagai pengganti yang disebut bioaspal. Salah satu bahan yang sedang dikembangkan saat ini adalah daspal (damar aspal). Tujuan dari penelitian ini adalah membandingkan benda uji daspal yang dibuat di laboratorium dengan benda uji hasil coring dari lapangan dengan variasi pemadatan menggunakan pengujian Marshall serta skid resistance. Metode yang digunakan pada penelitian ini adalah eksperimental di laboratorium dan lapangan. Adapun variasi pemadatan lapangan yang dilakukan yaitu 6 kali, 10 kali, dan 14 kali. Sebelum dilakukan proses coring, pengujian skid resistance dilakukan dengan alat rolling straightedge di lapangan. Coring pada setiap variasi pemadatan dilakukan guna mengambil benda uji untuk pengujian Marshall lapangan. Komposisi penyusun daspal adalah damar serbuk (350 gr), damar bongkahan (100 gr), minyak goreng (205 gr), fly ash (150 gr), dan lateks (4\%). Analisis hasil pengujian Marshall benda uji laboratorium didapatkan nilai stabilitas 1118,519 kg, flow 4,65 mm dan MQ 241,102 kg/mm. Nilai skid resistance 6 kali pemadatan 9,83 $\mathrm{mm} / \mathrm{m}, 10$ kali pemadatan $8,83 \mathrm{~mm} / \mathrm{m}$, dan 14 kali pemadatan $7,67 \mathrm{~mm} / \mathrm{m}$. Nilai stabilitas, flow, dan $M Q$ benda uji yang dibuat di laboratorium lebih besar daripada stabilitas, flow dan $M Q$ benda uji hasil coring dari lapangan dengan semua variasi pemadatan. Semakin besar nilai skid resistance mengindikasikan tekstur permukaan semakin rata.
\end{abstract}

Kata kunci : Daspal, Marshall, Skid Resistance

\section{PENDAHULUAN}

Penelitian ini dilakukan untuk mengetahui jumlah variasi pemadatan manakah yang paling tepat untuk digunakan supaya mendapatkan nilai stabilitas, kelelehan (flow), dan Marshall Quotient (MQ) yang sama antara benda uji laboratorium dengan benda uji lapangan, serta analisis skid resistance di lapangan. Manfaat penelitian ini adalah untuk menambah pengetahuan di bidang perkerasan jalan dengan bahan pengikat daspal, daspal sebagai alternative penggunaan bahan perkerasan yang ramah lingkungan (go green) dan dapat diperbarui (renewable) serta meningkatkan nilai ekonomis dari bahan-bahan penyusun pembuatan daspal.

Kekurangan dari penggunaan daspal adalah daspal dibuat dari bahan-bahan organik, sehingga memiliki jangka waktu penggunaan sebelum mulai mengalami perubahan sifat kandungannya karena proses pembusukan, pembuatan daspal yang masih manual membuat pemenuhan kebutuhan dalam jumlah yang 
banyak masih sulit terpenuhi. Bahan pengikat daspal yang digunakan terbuat dari damar serbuk (350 gr), damar bongkahan (100 gr), minyak goreng (205 gr), fly ash (150 gr), dan lateks (4\%) untuk sekali pemasakan.

\section{LANDASAN TEORI}

Bahan pengikat daspal dengan komposisi getah damar, fly ash, minyak goreng dan lateks memenuhi persyaratan aspal keras berdasarkan penetrasi RSNI-S-01-2013 untuk nilai penetrasi, titik lembek, daktilitas, titik nyala dan titik bakar, berat jenis, kelekatan, dan kelarutan jika menggunakan kadar lateks sebanyak 4 \%. (Zai, 2016). Analisis tentang sifat aspal beton menggunakan bahan pengikat daspal dengan komposisi getah damar, fly ash, minyak goreng dan lateks dengan kadar lateks $4 \%$ didapatkan hasil bahwa nilai kadar daspal optimum adalah sebesar 5,242\%. Setelah dilakukan pengujian Marshall, daspal memenuhi persyaratan dalam hal stabilitas, kepadatan (density), dan nilai Marshall Quotient (MQ). (Irfansyah, 2016).

\section{Laston}

Secara garis besar, laston memiliki ciri sedikit berongga didalam suatu struktur agregatnya sehingga ikatan satu agregat dengan agregat lainnya mengunci oleh karena itu aspal beton memiliki kekuatan dalam sifat stabilitas tinggi dan relatif kaku (Bina Marga Departemen Pekerjaan Umum 2010).

Berdasarkan fungsinya laston mempunyai 3 macam campuran dalam penggunaannya di lapangan yaitu :

1. Laston sebagai lapisan aus, dikenal dengan AC-WC. Tebal minimum lapisan AC-WC adalah $4 \mathrm{~cm}$.

2. Laston sebagai lapisan pengikat, dikenal dengan $A C-B C$. Tebal minimum lapisan $A C-B C$ adalah $5 \mathrm{~cm}$.

3. Laston sebagai lapisan pondasi, dikenal dengan AC-base. Tebal minimum lapisan AC-base adalah $6 \mathrm{~cm}$.

\section{METODE PENELITIAN}

Penelitian ini menggunakan metode eksperimental, yaitu metode yang dilakukan dengan mengadakan percobaan secara langsung di laboratorium dan di lapangan. Penelitian ini dilaksanakan di dua tempat, yaitu di Laboratorium Jalan Raya JTS FT UNS sebagai lokasi untuk perencanaan dan pengkonversian job mix design, pembuatan daspal, dan pengujian benda uji dari lapangan sedangkan di Desa Jeruksawit, Gondangrejo, Karanganyar sebagai lokasi untuk aplikasi penghamparan daspal di lapangan. Penelitian ini membandingkan nilai Marshall dari benda uji hasil laboratorium dengan benda uji dari penghamparan daspal di lapangan serta analisis skid resistance dengan 3 variasi jumlah pemadatan di lapangan.

Penelitian dibagi menjadi 4 tahapan, yaitu pembuatan benda uji pembanding di laboratorium, konversi job mix lapangan, penghamparan daspal di lapangan, dan pengujian serta analisis data. Konversi job mix lapangan dilakukan dengan mengubah volume perencanaan menjadi satuan berat. Pemadatan campuran daspal di lapangan dilakukan dengan mesin single drum roller.

\section{Pembuatan Benda Uji}

Benda uji untuk di laboratorium dan lapangan menggunakan bahan pengikat daspal.

Tabel 1. Jumlah Benda Uji

\begin{tabular}{ccc}
\hline Benda uji hasil laboratorium & \multicolumn{2}{c}{ Benda Uji Hasil Coring Lapangan } \\
\hline Jumlah Benda Uji & Jumlah Pemadatan & Jumlah Benda Uji \\
\hline (buah) & (kali) & (buah) \\
\hline \multirow{3}{*}{3} & 6 & 3 \\
\hline & 10 & 3 \\
\hline
\end{tabular}

\section{Pemadatan di Lapangan}

Variasi jumlah pemadatan yang dilakukan adalah 6, 10, dan 14 kali dengan menggunakan mesin single drum roller BOMAG $3-4$ ton (operating weight $=3300-3850 \mathrm{~kg}$, performance $=33.0$ deutz $\mathrm{kw}$ ).

Tabel 2. Rincian Pemadatan di Lapangan

\begin{tabular}{cccc}
\hline Variasi & \multicolumn{3}{c}{ Jumlah Pemadatan di Lapangan } \\
\cline { 2 - 4 } Pemadatan & awal & antara & akhir \\
\hline (kali) & (kali) & (kali) & (kali) \\
\hline 6 & 3 & 2 & 2 \\
\hline 10 & 3 & 4 & 3 \\
\hline 14 & 3 & 8 & 3 \\
\hline
\end{tabular}




\section{HASIL DAN PEMBAHASAN}

\section{Hasil Perencanaan Gradasi}

Dari hasil pemeriksaan agregat 3/4', 3/8' dan abu batu (stone dust), kemudian dilakukan perencanaan gradasi gabungan. Gradasi yang digunakan dalam penelitian ini adalah gradasi nomor VII yang terdapat di dalam SNI 03-1737-1989 (Tata Cara Pelaksanaan Lapis Aspal Beton Untuk Jalan Raya) dikarenakan fungsinya sebagai lapis permukaan, teksturnya rapat, dan sering digunakan pada perkerasan di Indonesia.

Tabel 3. Analisis Saringan Gabungan

\begin{tabular}{|c|c|c|c|c|c|c|c|c|c|}
\hline \multirow{3}{*}{$\begin{array}{c}\text { No. } \\
\text { Saringan }\end{array}$} & \multicolumn{6}{|c|}{ Jenis Agregat } & \multicolumn{3}{|c|}{ Kombinasi } \\
\hline & \multicolumn{2}{|c|}{ Agregat 3/4' } & \multicolumn{2}{|c|}{ Agregat 3/8' } & \multicolumn{2}{|c|}{ Abu Batu } & \multirow[t]{2}{*}{ Gradasi } & \multirow[t]{2}{*}{ Spec } & \multirow[t]{2}{*}{ Median } \\
\hline & $100,0 \%$ & $21,0 \%$ & $100,0 \%$ & $32,0 \%$ & $100,0 \%$ & $47,0 \%$ & & & \\
\hline $3 / 4^{\prime \prime}$ & 100,00 & 21,00 & 100,00 & 32,00 & 100,00 & 47,00 & 100,00 & $100-100$ & 100 \\
\hline $1 / 2^{\prime \prime}$ & 43,69 & 9,17 & 100,00 & 32,00 & 100,00 & 47,00 & 88,17 & $80-100$ & 90 \\
\hline$\# 4$ & 9,08 & 1,90 & 35,51 & 11,36 & 97,96 & 46,04 & 59,31 & 54-72 & 63 \\
\hline$\# 8$ & 4,97 & 1,04 & 13,91 & 4,45 & 93,74 & 44,05 & 49,55 & $42-58$ & 50 \\
\hline$\# 30$ & 2,82 & 0,59 & 4,94 & 1,58 & 68,07 & 31,99 & 34,16 & $26-38$ & 32 \\
\hline$\# 50$ & 1,69 & 0,35 & 4,02 & 1,28 & 42,52 & 19,98 & 21,62 & $18-28$ & 23 \\
\hline$\# 100$ & 1,31 & 0,27 & 2,54 & 0,81 & 26,51 & 12,45 & 13,54 & $12-20$ & 16 \\
\hline$\# 200$ & 0,58 & 0,12 & 0,95 & 0,30 & 15,44 & 7,25 & 7,68 & $6-12$ & 9 \\
\hline
\end{tabular}

\section{Hasil Pengujian Benda Uji Laboratorium}

Dengan menggunakan kadar daspal optimum sebesar 5,242\% dalam campuran pada benda uji laboratorium didapatkan hasil pengujian sebagai berikut :

Tabel 4. Hasil Pengujian Marshall Benda Uji Laboratorium

\begin{tabular}{|c|c|c|c|c|c|c|c|c|c|c|}
\hline \multirow{3}{*}{ Kode } & \multirow{2}{*}{$\begin{array}{c}\text { Tebal } \\
\text { Rata- } \\
\text { rata }\end{array}$} & \multicolumn{2}{|c|}{ Berat di Udara } & \multirow{2}{*}{$\begin{array}{l}\text { Berat } \\
\text { di Air }\end{array}$} & \multirow{2}{*}{$\begin{array}{c}\text { Koreksi } \\
\text { Tebal }\end{array}$} & \multicolumn{3}{|c|}{ Stabilitas } & \multirow{2}{*}{ Flow } & \multirow{2}{*}{$M Q$} \\
\hline & & Kering & SSD & & & Dial & Kalibrasi & Terkalibrasi & & \\
\hline & $(\mathrm{mm})$ & (gram) & (gram) & (gram) & & $(\mathrm{mm})$ & (kg) & (kg) & $(\mathrm{mm})$ & $(\mathrm{kg} / \mathrm{mm})$ \\
\hline L 1 & 61,575 & 1197,4 & 1200,0 & 702,80 & 1,050 & 46 & 1010,213 & 1060,881 & 4,85 & 218,738 \\
\hline L 2 & 61,250 & 1197,2 & 1199,9 & 702,67 & 1,060 & 50 & 1099,295 & 1165,596 & 4,48 & 260,177 \\
\hline L 3 & 60,925 & 1187,5 & 1190,6 & 698,80 & 1,070 & 48 & 1054,754 & 1129,081 & 4,62 & 244,389 \\
\hline & & & & ata & & & & 1118,519 & 4,65 & 241,102 \\
\hline
\end{tabular}

Tabel 5. Hasil Perhitungan Karakteristik Benda Uji Laboratorium

\begin{tabular}{ccccc}
\hline \multirow{2}{*}{ Kode } & Densitas & VIM & VMA & VFB \\
\cline { 2 - 5 } & $\left(\mathrm{gram} / \mathrm{cm}^{3}\right)$ & $(\%)$ & $(\%)$ & $(\%)$ \\
\hline L 1 & 2,408 & 1,947 & 12,589 & 84,528 \\
\hline L 2 & 2,407 & 1,970 & 12,609 & 84,375 \\
\hline L 3 & 2,414 & 1,690 & 12,360 & 86,320 \\
\hline Rata - rata & 2,410 & 1,869 & 12,520 & 85,075 \\
\hline
\end{tabular}

\section{Job Mix Lapangan}

Konversi job mix laboratorium menjadi job mix lapangan dilakukan dalam tiga tahapan. Tahapan pertama adalah menghitung volume penghamparan lapangan. Tahapan kedua adalah menghitung kebutuhan total materian dalam satuan berat dengan densitas benda uji laboratorium. Tahap ketiga menghitung masingmasing kebutuhan material. 
Tabel 6. Perhitungan Job Mix Lapangan

\begin{tabular}{lcc}
\hline Volume Penghamparan & $300 \times 100 \times 6$ & $180.000 \mathrm{~cm}^{3}$ \\
\hline Kebutuhan Total Material & $180.000 / 2,410$ & $434 \mathrm{~kg}$ \\
\hline Daspal & $434 \mathrm{~kg} \times 5,242 \%$ & $22,751 \mathrm{~kg}$ \\
\hline Agregat 3/4' & $(434-22,751) \mathrm{kg} \mathrm{x} \mathrm{21 \%}$ & $86,362 \mathrm{~kg}$ \\
\hline Agregat 3/8' & $(434-22,751) \mathrm{kg} \times 32 \%$ & $131,599 \mathrm{~kg}$ \\
\hline Abu Batu & $(434-22,751) \mathrm{kg} \mathrm{x} \mathrm{47 \%}$ & $193,286 \mathrm{~kg}$ \\
\hline
\end{tabular}

\section{Hasil Pengujian Benda Uji Lapangan}

Benda uji lapangan diperoleh dari hasil coring campuran daspal yang telah dihamparkan dan dipadatkan dengan 3 variasi jumlah pemadatan.

Tabel 7. Hasil Pengujian Marshall Benda Uji Lapangan

\begin{tabular}{|c|c|c|c|c|c|c|c|c|c|c|}
\hline \multirow{3}{*}{ Kode } & \multirow{3}{*}{$\begin{array}{c}\text { Tebal } \\
\text { Rata- } \\
\text { rata } \\
(\mathrm{mm})\end{array}$} & \multicolumn{2}{|c|}{ Berat di Udara } & \multirow{2}{*}{$\begin{array}{l}\text { Berat } \\
\text { di Air }\end{array}$} & \multirow{3}{*}{$\begin{array}{c}\text { Koreksi } \\
\text { Tebal }\end{array}$} & \multicolumn{3}{|c|}{ Stabilitas } & \multirow{2}{*}{ Flow } & \multirow{2}{*}{$M Q$} \\
\hline & & Kering & SSD & & & Dial & Kalibrasi & Terkalibrasi & & \\
\hline & & (gram) & (gram) & (gram) & & $(\mathrm{mm})$ & $(\mathrm{kg})$ & $(\mathrm{kg})$ & $(\mathrm{mm})$ & $(\mathrm{kg} / \mathrm{mm})$ \\
\hline $6 \mathrm{~A}$ & 47,937 & 547,80 & 582,50 & 320,10 & 1,646 & 15 & 332,865 & 548,161 & 3,72 & 147,355 \\
\hline $6 \mathrm{~B}$ & 51,650 & 724,40 & 735,80 & 415,70 & 1,427 & 17 & 377,247 & 538,520 & 3,65 & 147,539 \\
\hline $6 \mathrm{C}$ & 46,300 & 539,60 & 566,10 & 319,20 & 1,767 & 14 & 310,674 & 549,116 & 3,67 & 149,622 \\
\hline \multicolumn{8}{|c|}{ Rata-rata } & 545,265 & 3,68 & 148,172 \\
\hline $10 \mathrm{~A}$ & 45,787 & 530,20 & 554,20 & 312,20 & 1,807 & 19 & 421,629 & 761,995 & 3,61 & 211,079 \\
\hline $10 \mathrm{~B}$ & 52,725 & 725,70 & 752,90 & 424,70 & 1,375 & 21 & 465,458 & 640,369 & 3,55 & 180,385 \\
\hline $10 \mathrm{C}$ & 51,525 & 714,20 & 746,10 & 417,30 & 1,433 & 21 & 465,458 & 667,351 & 3,52 & 189,588 \\
\hline \multicolumn{8}{|c|}{ Rata-rata } & 689,905 & 3,56 & 193,684 \\
\hline $14 \mathrm{~A}$ & 49,275 & 679,60 & 692,70 & 399,70 & 1,555 & 23 & 508,735 & 791,481 & 3,52 & 224,852 \\
\hline $14 \mathrm{~B}$ & 52,100 & 725,00 & 750,10 & 422,30 & 1,405 & 24 & 530,374 & 745,175 & 3,46 & 215,368 \\
\hline $14 \mathrm{C}$ & 45,887 & 530,50 & 560,70 & 312,50 & 1,799 & 19 & 421,629 & 758,569 & 3,44 & 220,514 \\
\hline \multicolumn{8}{|c|}{ Rata-rata } & 765,075 & 3,47 & 220,245 \\
\hline
\end{tabular}

Tabel 8. Hasil Perhitungan Karakteristik Benda Uji Lapangan

\begin{tabular}{ccccc}
\hline \multirow{2}{*}{ Kode } & Densitas & VIM & VMA & VFB \\
\cline { 2 - 5 } & $\left(\mathrm{gram}^{\mathrm{cm}} \mathrm{cm}^{3}\right)$ & $(\%)$ & $(\%)$ & $(\%)$ \\
\hline 6 A & 2,087 & 15,002 & 24,227 & 38,077 \\
\hline 6 B & 2,263 & 7,861 & 17,861 & 55,987 \\
\hline 6 C & 2,185 & 11,018 & 20,676 & 46,709 \\
\hline Rata - rata & 2,178 & 11,294 & 20,921 & 46,924 \\
\hline 10 A & 2,190 & 10,798 & 20,479 & 47,273 \\
\hline 10 B & 2,211 & 9,974 & 19,745 & 49,485 \\
\hline 10 C & 2,172 & 11,562 & 21,161 & 45,359 \\
\hline Rata - rata & 2,191 & 10,778 & 20,461 & 47,372 \\
\hline 14 A & 2,319 & 5,564 & 15,814 & 64,812 \\
\hline 14 B & 2,211 & 9,951 & 19,724 & 49,549 \\
\hline 14 C & 2,137 & 12,977 & 22,422 & 42,123 \\
\hline Rata - rata & 2,222 & 9,497 & 19,320 & 52,161 \\
\hline
\end{tabular}




\section{Perbandingan Hasil Pengujian Benda Uji Laboratorium dengan Benda Uji Lapangan}

a. Perbandingan Stabilitas Laboratorium dengan Lapangan

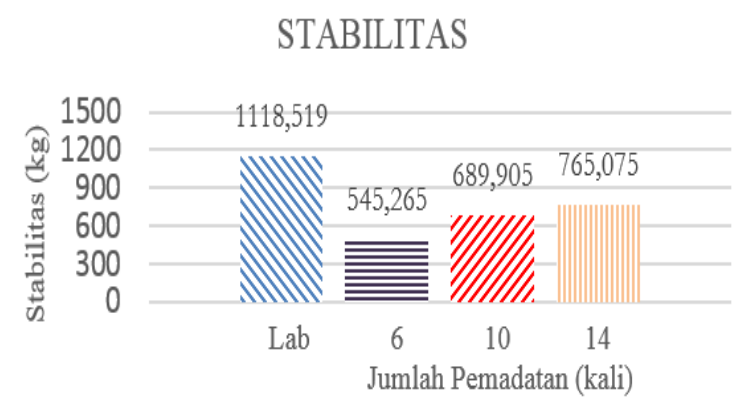

Gambar 1. Grafik Perbandingan Stabilitas Laboratorium dengan Lapangan

Menunjukkan bahwa semakin banyak jumlah pemadatan sampai jumlah tertentu yang dilakukan di lapangan akan menghasilkan nilai stabilitas yang mendekati nilai stabilitas benda uji laboratorium.

b. Perbandingan Flow Laboratorium dengan Lapangan

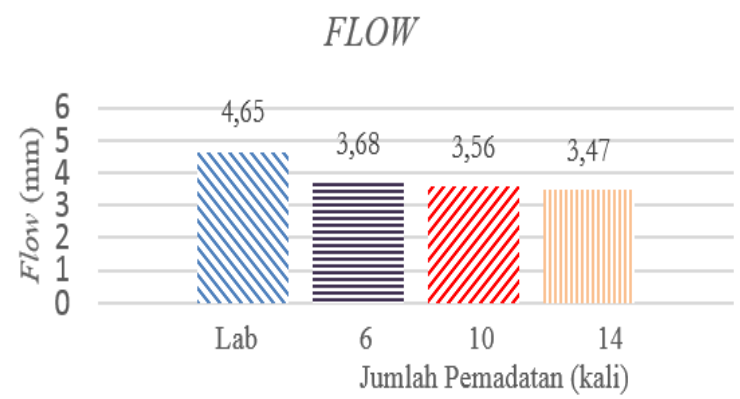

Gambar 2. Grafik Perbandingan Flow Laboratorium dengan Lapangan

Menunjukkan bahwa kadar daspal dalam campuran benda uji laboratorium lebih terkontrol dan menghasilkan nilai flow yang lebih tinggi dibandingkan dengan benda uji lapangan yang memiliki skala yang lebih besar dan jumlah kebutuhan bahan pengikat daspal yang lebih banyak sehingga kontrol kadar daspal campuran berkurang dan menyebabkan nilai flow lapangan turun. Kondisi bahan pengikat daspal yang disimpan terlalu lama juga ikut mempengaruhi nilai flow.

c. Perbandingan $M Q$ Laboratorium dengan Lapangan

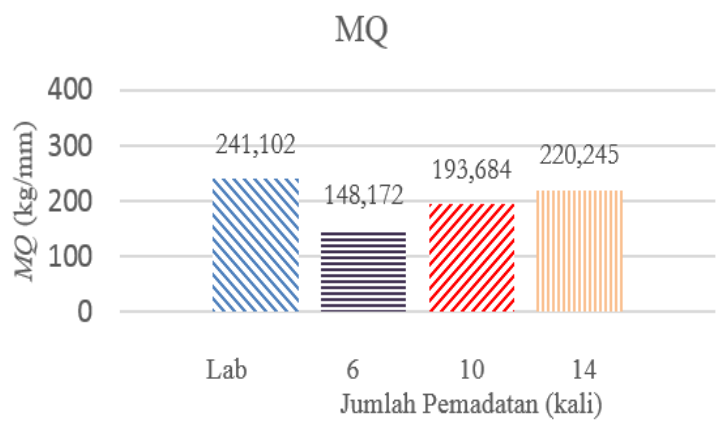

Gambar 3. Grafik Perbandingan $M Q$ Laboratorium dengan Lapangan

Menunjukkan bahwa nilai $M Q$ ditentukan oleh nilai stabilitas dan flow dari benda uji, baik itu benda uji dari laboratorium maupun dari lapangan.

d. Rekapitulasi Perbandingan Hasil Pengujian Benda Uji Laboratorium dengan Benda Uji Lapangan 
Tabel 9. Rekapitulasi Perbandingan Hasil Pengujian Benda Uji Laboratorium dengan Lapangan

\begin{tabular}{|c|c|c|c|c|c|}
\hline $\begin{array}{l}\text { Kadar } \\
\text { Daspal }\end{array}$ & & Stabilitas & Flow & $M Q$ & $\begin{array}{c}\text { Kepadatan } \\
\text { Relatif }\end{array}$ \\
\hline$(\%)$ & & $(\mathrm{kg})$ & $(\mathrm{mm})$ & $(\mathrm{kg} / \mathrm{mm})$ & $(\%)$ \\
\hline \multirow{5}{*}{5,242} & Laboratorium & 1118,519 & 4,65 & 241,102 & - \\
\hline & Lapangan: & & & & \\
\hline & $6 \mathrm{kali}$ & 545,265 & 3,68 & 148,172 & 90,39 \\
\hline & 10 kali & 689,905 & 3,56 & 193,684 & 90,92 \\
\hline & 14 kali & 765,075 & 3,47 & 220,245 & 92,22 \\
\hline
\end{tabular}

Dapat dilihat bahwa benda uji laboratorium memiliki nilai stabilitas, flow, dan $M Q$ paling besar. Semakin banyak variasi jumlah pemadatan, nilai stabilitas dan $M Q$ akan naik, sedangkan nilai flow akan turun.

\section{Hasil Pengujian Skid Resistance}

Pengujian skid resistance dilakukan di lapangan sebelum pengambilan benda uji lapangan (coring), dalam pengujian ini didapatkan nilai Profil Ride Index (PRI) untuk mengetahui tingkat kerataan suatu jalan. Alat yang digunakan dalam pengujian ini bernama rolling straightedge.

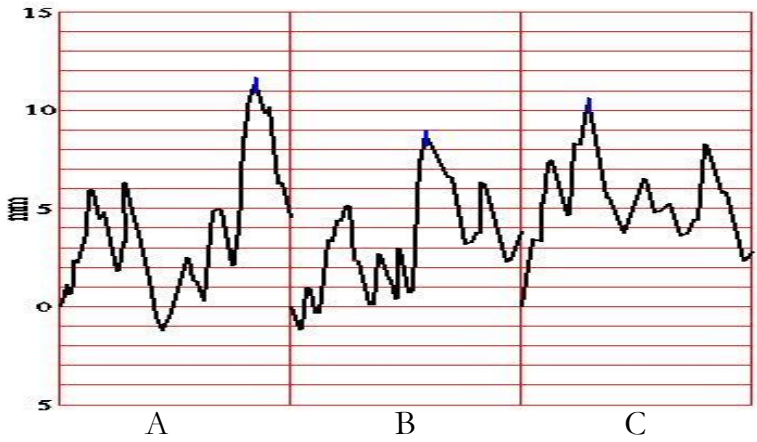

Gambar 4. Grafik 6 Kali Pemadatan

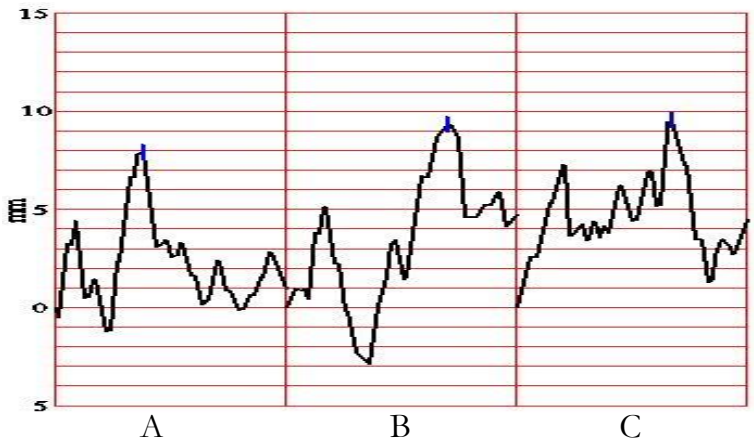

Gambar 5. Grafik 10 Kali Pemadatan

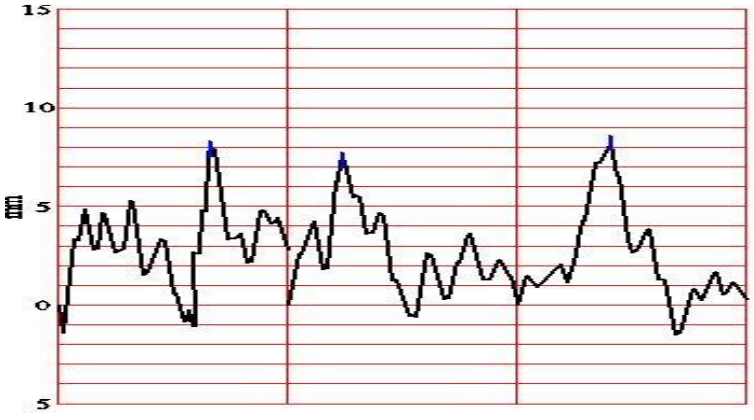

Gambar 6. Grafik 
Tabel 10. Hasil Pengujian Rolling Straightedge

\begin{tabular}{cccc}
\hline \multirow{2}{*}{ Kode } & $\begin{array}{c}\text { PrI Zero Null Band } \\
\text { 6 Kali Pemadatan }\end{array}$ & $\begin{array}{c}\text { PrI Zero Null Band } \\
\text { 10 Kali Pemadatan }\end{array}$ & $\begin{array}{c}\text { PrI Zero Null Band } \\
\text { 14 Kali Pemadatan }\end{array}$ \\
\cline { 2 - 4 } & $(\mathrm{mm} / \mathrm{meter})$ & $(\mathrm{mm} / \mathrm{meter})$ & $(\mathrm{mm} / \mathrm{meter})$ \\
\hline A & 11,0 & 8,0 & 8,0 \\
\hline B & 8,5 & 9,0 & 7,0 \\
\hline C & 10,0 & 9,5 & 8,0 \\
\hline Rata-Rata & 9,83 & 8,83 & 7,67 \\
\hline
\end{tabular}

Menunjukkan bahwa nilai $\operatorname{Pr}$ mengalami penurunan dari 6, 10 sampai 14 kali pemadatan. PrI untuk segmen 14 kali pemadatan menunjukkan nilai yang kecil, hal ini berarti tekstur permukaan yang dimiliki segmen 14 kali pemadatan lebih halus dan rata dibandingkan dengan segmen lainnya. Sedangkan PrI untuk segmen 6 kali pemadatan menunjukkan nilai $\operatorname{PrI}$ yang lebih besar daripada segmen yang lainnya, hal ini berarti tekstur permukaan yang dimiliki segmen 6 kali pemadatan lebih kasar dan bergelombang daripada segmen lainnya.

\section{KESIMPULAN DAN SARAN}

\section{Kesimpulan}

Setelah dilakukan penelitian dan analisis data didapat kesimpulan sebagai berikut :

1. Nilai stabilitas, flow dan $M Q$ benda uji daspal yang dibuat di laboratorium memiliki nilai yang lebih besar daripada benda uji hasil coring lapangan dengan semua variasi jumlah pemadatan dengan nilai :

a. Stabilitas benda uji hasil laboratorium sebesar 1118,519 kg serta benda uji lapangan 6 kali pemadatan $545,265 \mathrm{~kg}, 10 \mathrm{kali}$ pemadatan 689,905 kg dan 14 kali pemadatan 765,075 kg.

b. Flow benda uji hasil laboratorium sebesar $4,65 \mathrm{~mm}$ serta benda uji lapangan 6 kali pemadatan 3,68 $\mathrm{mm}, 10$ kali pemadatan $3,56 \mathrm{~mm}$ dan 14 kali pemadatan 3,47 $\mathrm{mm}$.

c. $M Q$ benda uji hasil laboratorium sebesar $241,102 \mathrm{~kg} / \mathrm{mm}$ serta benda uji lapangan 6 kali pemadatan

$148,172 \mathrm{~kg} / \mathrm{mm}, 10 \mathrm{kali}$ pemadatan 193,684 kg/mm dan $14 \mathrm{kali}$ pemadatan 220,245 kg/mm.

2. Nilai skid resistance daspal yang telah dihamparkan di lapangan dengan 6 kali pemadatan sebesar 9,83 $\mathrm{mm} /$ meter, 10 kali pemadatan sebesar $8,83 \mathrm{~mm} /$ meter dan 14 kali pemadatan sebesar 7,67 mm/meter.

\section{Saran}

1. Penelitian lebih lanjut disarankan untuk melakukan penelitian yang lebih mendalam dan persiapan yang matang agar hasil benda uji laboratorium dengan lapangan memenuhi persyaratan dan spesifikasi.

2. Penelitian selanjutnya diharapkan menggunakan variasi jumlah pemadatan yang lebih banyak.

3. Penelitian selanjutnya apabila menggunakan alat rolling straightedge, disarankan untuk menghamparkan campuran daspal minimal sepanjang 10 meter supaya grafik yang didapat lebih mudah untuk dianalisis.

\section{UCAPAN TERIMA KASIH}

Allah SWT yang telah memberikan banyak nikmat-Nya sehingga penelitian ini dapat terselesaikan, orang tua tercinta yang selalu memberikan dukungan tiada henti, Ir. Ary Setyawan, M.Sc., Ph.D. dan Ir. Agus Sumarsono, M.T. yang telah banyak membimbing dan memberikan arahan dalam penulisan penelitian ini, serta teman-teman sipil seperjuangan.

\section{REFERENSI}

Abraham, Fieza Emha. 2016. Evaluasi Karaktersitik Marshall Pada Campuran Aspal Dengan Damar Aspal (DASPAL) Sebagai Bahan Pengikat. Surakarta: Universitas Sebelas Maret.

Anonim. 2005. Buku Pedoman Penulisan Tugas Akhir. Jurusan Teknik Sipil Fakultas Teknik Universitas Sebelas Maret. Surakarta. 
Departemen Pekerjaan Umum. 1990. SNI 03-1968-1990 Metode Pengujian Tentang Analisis Saringan Agregat Halus dan Kasar. Badan Penelitian dan Pengembangan PU.

Departemen Pekerjaan Umum. 1991. SNI 03-1737-1989 Tata Cara Pelaksanaan Lapis Aspal Beton (Laston) Untuk Jalan Raya. Badan Penelitian dan Pengembangan PU.

Departemen Pekerjaan Umum. 2003. RSNI S-01-2003 Spesifikasi aspal keras berdasarkan penetrasi. Badan Penelitian dan Pengembangan PU.

Departemen Pekerjaan Umum. 2010. Rancangan Spesifikasi Umum Bidang Jalan dan Jembatan. Bandung. Puslitbang Jalan dan Jembatan Badan Penelitian dan Pengembangan.

Departemen Pekerjaan Umum. 2010. Spesifikasi Umum Bina Marga 2010 Divisi 6 Revisi 3. Badan Penelitian dan Pengembangan PU.

Irfansyah, Permana Adi. 2016. Karaktersitik Marshall Pada Campuran Aspal Beton Menggunakan Daspal Modifikasi Sebagai Bahan Pengikat. Surakarta: Universitas Sebelas Maret.

Jennings, Aaron dan R. Hill, Daniel. 2011. Bioasphalt from Urban Yard Carbonization. Ohio : Departmet of Transportation Office of Research and Development

Mulyono, N., \& Apriyantono, A., 2010. Brief Review on: Physical, Chemical and Functional Properties of Dammar. Jurnal Teknologi Dan Industri Pangan, 15(3), 245.

Nasution, Muhammad Fachri. 2015. Studi Karakteristik Damar Aspal Berdasarkan Penetration Grade Dibandingkan Dengan Aspal Pertamina Dan Asbuton. Surakarta: Universitas Sebelas Maret.

Prasetyo, Yudhi Mahadi. 2016. Studi Banding Karakteristik Beton Berpori Antara Benda Uji di Laboratorium Dengan Benda Uji di Lapangan (Studi Kasus Pada Bahu Jalan di Desa Kadokan, Kecamatan Grogol, Kabupaten Sukoharjo). Surakarta : Universitas Sebelas Maret.

Sukirman, Silvia. 1999. Perkerasan Lentur Jalan Raya. Bandung : Nova.

Sukirman, Silvia. 2003. Beton Aspal Campuran Panas. Yogyakarta: Yayasan Obor Indonesia.

Yhudianto, Bondan. 2017. Pengarub Pengisisan Rongga Pada Perkerasan Aspal Porus Terbadap Kecepatan Resapan, Permeabilitas dan Skid Resistance. Surakarta: Universitas Sebelas Maret.

Zai, Soniel Aroman. 2016. Studi Karakteristik Damar Aspal (Daspal) Modifikasi Dengan Kombinasi Material Getah Damar, Fy Ash, Minyak Goreng, dan Lateks Dibandingkan Dengan Aspal Penetrasi 40/50 dan Aspal Penetrasi 60/70. Surakarta: Universitas Sebelas Maret. 